\title{
Cost-of-illness studies in heart failure: a systematic review 2004-2016
}

Wladimir Lesyuk ${ }^{1,2^{*}}$ (D) Christine Kriza ${ }^{1,2}$ and Peter Kolominsky-Rabas ${ }^{1,2}$

\begin{abstract}
Background: Heart failure is a major and growing medical and economic problem worldwide as $1-2 \%$ of the healthcare budget are spent for heart failure. The prevalence of heart failure has increased over the past decades and it is expected that there will be further raise due to the higher proportion of elderly in the western societies. In this context cost-of-illness studies can significantly contribute to a better understanding of the drivers and problems which lead to the increasing costs in heart failure.

The aim of this study was to perform a systematic review of published cost-of-illness studies related to heart failure to highlight the increasing cost impact of heart failure.

Methods: A systematic review was conducted from 2004 to 2016 to identify cost-of-illness studies related to heart failure, searching PubMed (Medline), Cochrane, Science Direct (Embase), Scopus and CRD York Database.

Results: Of the total of 16 studies identified, 11 studies reported prevalence-based estimates, 2 studies focused on incidence-based data and 3 articles presented both types of cost data. A large variation concerning cost components and estimates can be noted. Only three studies estimated indirect costs. Most of the included studies have shown that the costs for hospital admission are the most expensive cost element. Estimates for annual prevalence-based costs for heart failure patients range from $\$ 868$ for South Korea to $\$ 25,532$ for Germany. The lifetime costs for heart failure patients have been estimated to $\$ 126.819$ per patient.
\end{abstract}

Conclusions: Our review highlights the considerable and growing economic burden of heart failure on the health care systems. The cost-of-illness studies included in this review show large variations in methodology used and the cost results vary consequently. High quality data from cost-of-illness studies with a robust methodology applied can inform policy makers about the major cost drivers of heart failure and can be used as the basis of further economic evaluations.

Keywords: Heart failure, Cost-of-illness, Economic burden, Heart disease

\section{Background}

\section{The burden of heart failure}

Heart failure (HF) is a major and growing medical and economic problem, with high prevalence and incidence rates worldwide $[1,2]$. HF is defined as a pathophysiological state in which an abnormality of cardiac function is responsible for the failure of the heart to pump blood at a rate commensurate with the requirements of the metabolizing tissues [3]. It has been estimated that $0.4-2.2 \%$ of the population in industrialized countries suffer from HF [4], with between 500,000-600,000 incident cases

\footnotetext{
* Correspondence: wladimir.lesyuk@uk-erlangen.de

${ }^{1}$ Centre for Health Technology Assessment (HTA) and Public Health (IZPH),

Friedrich-Alexander-University Erlangen-Nürnberg, Erlangen, Germany

${ }^{2}$ National Leading-Edge Cluster Medical Technologies 'Medical Valley EMN',

Erlangen, Bavaria, Germany
}

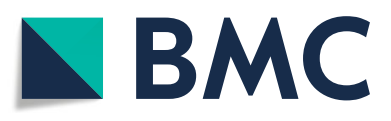

(๑) The Author(s). 2018 Open Access This article is distributed under the terms of the Creative Commons Attribution 4.0 International License (http://creativecommons.org/licenses/by/4.0/), which permits unrestricted use, distribution, and

reproduction in any medium, provided you give appropriate credit to the original author(s) and the source, provide a link to the Creative Commons license, and indicate if changes were made. The Creative Commons Public Domain Dedication waiver (http://creativecommons.org/publicdomain/zero/1.0/) applies to the data made available in this article, unless otherwise stated. with $80 \%$ of HF-related hospitalizations and $90 \%$ of HFrelated deaths occurring among patients aged 65 years or older [6]. The prevalence of HF has increased over the past decades [7]. It is expected that there will be a further rise due to a higher proportion of elderly people and better survival rates of patients with conditions such as hypertension, diabetes, etc., which trigger the development of $\operatorname{HF}[7,8]$. In addition, two thirds of the patients are readmitted to hospital within one year [9]. The mortality rate for patients with HF is high, as showed in the MAGGIC meta-analysis includes individual data on 39,372 patients with $40,2 \%$ died during a median follow-up of 2,5 years [10]. A recently published study demonstrated that the 30-day readmission 
rates for HF are higher than for pneumonia or acute myocardial infarction [11].

Due to the high and increasing prevalence rates, HF constitutes an enormous economic burden for the healthcare systems in industrialized countries. For example, Europa and USA spent $1-2 \%$ of their annual healthcare budget on HF [6]. The global economic burden of HF is estimated at $\$ 108$ billons per annum, with $\$ 65$ billons attributed to direct and $\$ 43$ billons to indirect costs [12]. The US is the biggest contributor to the global HF costs and is responsible for $28.4 \%$ of total global HF spend [12]. Europa accounts for $6.83 \%$ of total global HF costs [12].

Due to the considerable cost impact of HF on healthcare systems, it is necessary to have a better understanding of the cost aspects and the specific cost drivers. In this context, Cost-of-Illness (COI) studies are an important tool to analyze the economic burden of HF and to provide information on the cost drivers to clinicians and health policy makers. On the basis of transparent and detailed cost components this is aimed at improving the planning and development of healthcare services and optimization of the allocation of healthcare expenditures and medical resources [13]. COI studies are often restricted to a certain country, deal with small patient groups or present only a part of all illness costs. Therefore, it is important to summarize the results of different COI-studies in a systematic way.

\section{Background on cost-of-illness studies}

COI studies estimate the resources consumed and lost as a result of a particular disease. Results from the COI studies can improve understanding of the economic burden that a specific disease may have on society as whole, healthcare providers, and the individual patient. COI studies can also provide a fundamental basis for further economic evaluations, such as cost-effectiveness-, costutility- and cost-benefit analysis [14].

\section{Perspective}

COI studies can be conducted from various perspectives. Based on the chosen perspective, the cost estimation can vary. The most popular perspectives are the societal perspective and the viewpoints of the patient, the insurance company or the healthcare providers.

\section{Epidemiological approach}

COI studies follow two different epidemiological approaches, either the prevalence- or the incidence-based approach. Prevalence-based studies measure costs, which occur with prevalent cases over a specified time period, usually 1 year [15].

The incidence-based approach focusses on lifetime costs attributed to a disease. The costs are measured from the onset of a disease [15].

\section{Method of resource quantification}

COI studies use two different methods to estimate costs. The bottom-up approach ("person-based") assigns costs to individuals with the health condition of interest, for example by using data from real cases [15]. The topdown method ("population-based") allocates parts of aggregated costs to specific diseases.

\section{Objectives}

The aim of this study was to perform a systematic review of recently published COI studies related to HF to highlight the increasing cost impact associated with this disease and identify the major cost drivers.

\section{Methods}

We conducted a systematic literature search for journal articles between 2004 and 2016 in the following databases: PubMed (Medline), Cochrane, Science Direct (Embase), Scopus and CRD (Centre for Reviews and Dissemination) York Database incl. National Health Service Economics Evaluation Database (NHS EED). To identify relevant COIstudies for HF, appropriate disease-related $\mathrm{MeSH}$ terms were used (Additional file 1). The references or citations of the retrieved articles were reviewed for additional articles (citation snowballing). The search methodology was in line with the PRISMA (Preferred Reporting Items for Systematic Reviews and Meta-Analyses) guidelines [16] except for the use of the PICOS (population, intervention, comparators, outcomes, study design) review system.

\section{Inclusion and exclusion criteria}

Search results were transferred to EndNote, version X7, and reviewed independently by two researchers. The inclusion and exclusion criteria were adopted from the CHEC list [17] and the BMJ guidelines for authors and peer reviewers of economic submissions [18]. Although the two checklists were developed for the assessment of economic evaluations, we derived criteria that are also relevant for the evaluation of cost-of-illness studies. These criteria are listed in the appendix (Additional file 2). Furthermore they were in accordance with the check list for COI evaluation in the guide to critical evaluation of COI studies developed by Larg et al. [15].

HF can be categorized in two entities, systolic HF and diastolic HF. Systolic heart failure is defined as the entity in which the ejection fraction is reduced. In diastolic HF the ejection fraction is preserved. Owan et al. has shown that $53 \%$ of patients suffer from systolic and $47 \%$ from diastolic heart failure [19]. As our aim was to analyze all entities of HF independently of the pathophysiologic mechanism, we excluded papers dealing only with systolic/diastolic HF.

\section{General characteristics of the studies}

To provide a comprehensive understanding, the included studies were analyzed in terms of country, epidemiological 
approach (prevalent vs. incident), study period, perspective (societal, healthcare provider, etc.), main data sources and the identification of HF patients. When the study perspective or the epidemiological approach were not clearly specified in the studies, two investigators achieved consensus by discussion.

\section{Standardization of costs}

The reported costs in the included studies were transferred from the local currency in the year of the costs to the inflated values in local currency for the year 2016 [20]. This cost data was exchanged to US-dollars by using the gross domestic product purchasing power parity (PPP) [21]. This methodology can be used for COI studies in order to reach better comparability between the different currencies [22].

\section{Results}

The search procedure is shown in the PRISMA Flow Diagram (Fig. 1: Data acquisition flowchart). The systematic literature search identified 17,329 potential relevant articles. After removing 9166 duplicates, there were 8163 studies, which were screened by title and abstract. 8068 papers were excluded because they did not deal with COI studies of HF. Of the remaining 95 articles, another 79 studies did not fulfill the inclusion criteria shown in the Appendix. In all, 16 articles were identified in this review and analyzed by their study characteristics and cost data.

\section{Study characteristics}

Study characteristics are summarized in Tables 1 and 2 . Reviewed COI studies showed results for ten countries. Eight studies were conducted in Europa, and six in North America. The study population size ranged from a minimum of 115 to a maximum of 475,019 . The mean age of the study population varied from 58 to 81.6 years. Three studies [23-25] reported the mean age of different subgroups (HF-group vs. no-HF control group). Eleven articles had a prevalent and two an incident epidemiological approach. Three studies provided both types of results [25-27]. Twelve studies adopted the perspective

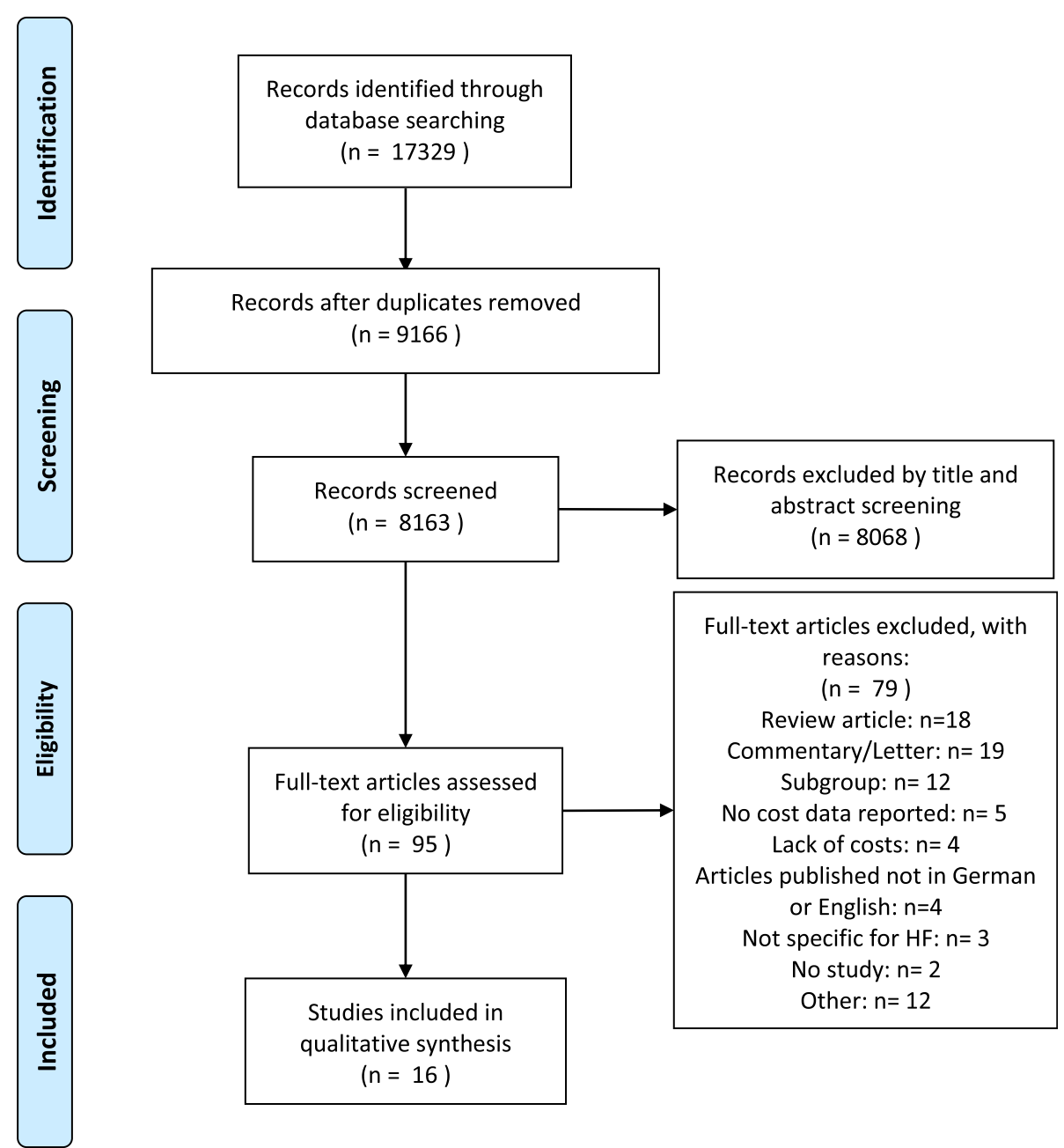

Fig. 1 Data acquisition flowchart 
Table 1 COl-studies in HF: Summary of main study characteristics

\begin{tabular}{|c|c|c|c|c|c|c|c|c|}
\hline Reference & Country & Study size & $\begin{array}{l}\text { Epidemiological } \\
\text { approach }\end{array}$ & $\begin{array}{l}\text { Method of Resource } \\
\text { Quantification }\end{array}$ & Study period & Perspective & Study design & Mean age \\
\hline Voigt 2014 [35] & USA & - & Prevalent ${ }^{a}$ & Mixed $^{\mathrm{a}}$ & 2007-2012 & $S^{a}$ & $\mathrm{R}$ & - \\
\hline Corrao 2014 [33] & Italy & 26,949 & Incident & Top-down ${ }^{a}$ & 2011 & $P$ & R & 79 \\
\hline Czech 2013 [36] & Poland & - & Prevalent $^{\mathrm{a}}$ & Mixed $^{a}$ & 2009-2011 & $P$ & $\mathrm{R}$ & - \\
\hline Delgado 2013 [37] & Spain & 374 & Prevalent $^{a}$ & Bottom-up ${ }^{a}$ & 2010 & S & $\operatorname{Pr}$ & 62 \\
\hline Dunlay 2011 [34] & USA & 1054 & Incident $^{\mathrm{a}}$ & Top-down ${ }^{a}$ & 1987-2006 & $p^{a}$ & R & 76,8 \\
\hline Bogner 2010 [24] & USA & 7996 & Prevalent ${ }^{\mathrm{a}}$ & Bottom-up ${ }^{a}$ & 2000-2001 & $P$ & $\mathrm{R}$ & $77,8-81,4$ \\
\hline Zugck 2010 [30] & Germany & 86,493 & Prevalent $^{\mathrm{a}}$ & Top-down ${ }^{a}$ & 2002 & $p^{a}$ & $\mathrm{R}$ & - \\
\hline Neumann 2009 [29] & Germany & - & Prevalent $^{a}$ & Top-down ${ }^{a}$ & 2000-2007 & $p^{a}$ & R & - \\
\hline Liao 2007 [23] & USA & 4860 & Prevalent & Top-down & 1992-2003 & $P^{a}$ & $\operatorname{Pr}$ & $75,6-78,2$ \\
\hline Liao 2006 [25] & USA & 881 & Mixed & Top-down & 1992-1998 & $P^{a}$ & $\operatorname{Pr}$ & $77,6-81,6$ \\
\hline Agvall 2005 [28] & Sweden & 115 & Prevalent $^{a}$ & Bottom-up ${ }^{a}$ & 1999-2000 & $P^{a}$ & R & 77 \\
\hline Ory 2005 [26] & USA & 17,835 & Mixed & Bottom-up ${ }^{a}$ & 1999-2001 & $P^{a}$ & $\operatorname{Pr}$ & 76,4 \\
\hline Stafylas 2016 [38] & Greece & 307 & Prevalent & Top-down ${ }^{a}$ & 2009-2011 & $P$ & $\operatorname{Pr}$ & 66 \\
\hline Lee 2016 [31] & South Korea & 475,019 & Prevalent & Top-down & 2014 & $P / S$ & $\mathrm{R}$ & - \\
\hline Murphy 2016 [27] & Ireland & 1292 & Mixed $^{a}$ & Mixed $^{a}$ & 2013 & $p^{a}$ & $R$ & 74,5 \\
\hline Ogah 2014 [32] & Nigeria & 239 & Prevalent & Mixed $^{\mathrm{a}}$ & 2009-2010 & S & $\operatorname{Pr}$ & 58 \\
\hline
\end{tabular}

anot clearly stated in the study, consensus by discussion

$\mathrm{S}$ - societal; $\mathrm{P}$ - third-party payer; $\mathrm{R}$ - retrospective; $\mathrm{Pr}$ - prospective

of a third-party payer and six articles were categorized as a prospective study.

To identify HF patients, the studies used different methods. Six articles referred to the ICD-10 (International Classification of Diseases), [27-32], five to the ICD-9 [24, 26, 33-35] and five [23, 25, 36-38] didn't specify the ICD classification.

Because HF is usually accompanied by many underlying diseases, it is often difficult to identify the correct cases of HF based on the diagnosis codes of ICD. Lee et al. [31] showed that by defining HF only as the primary diagnosis the HF cases decrease by $46 \%$ in contrast to define HF cases as primary and secondary diagnosis (using the same ICD-codes). By further analyzes he showed, that $75 \%$ of patients with HF, which was defined as a secondary diagnosis had a primary diagnosis which was related to HF, such as hypertension or angina pectoris. Thus, defining HF only as the primary diagnosis might lead to an under-specification of HF [31].

A second study of Voigt et al. [35] calculated costs for $\mathrm{HF}$ as the primary diagnosis (HF in isolation, $\mathrm{HFI}$ ) and $\mathrm{HF}$ as one of multiple diagnosis/part of a disease milieu (HF syndrome, HFS). As a consequence, costs range between 70.8 (HFI)- 127.0 (HFS) billion dollars. This might show the great underestimation of economic burden, if defining HF only as the primary diagnosis [35].

\section{Epidemiological data}

HF shows high prevalence rates with 12.4 per 1000 persons suffering from this chronic condition [31]. The prevalence rates increase with age $[29,31,36]$, with patients aged 65 or older showed 9.2-fold higher prevalence and 1.6 higher costs than 19-64 aged population [31]. Neumann et al. [29] analyzed that patients 65 or older shows 10-times higher prevalence rates than $45-65$ aged patients.

Incidence rates are also high with $2.4-3.8$ per 1000 persons [33]. HF results in a severe mortality rate with 1 -year mortality after HF hospitalization of $24 \%$ [33]. Stafylas et al. [38] showed that the mortality rates are higher for patients, who were hospitalized for HF $(24,3 \%)$ than for HF patients treated outpatient $(7,7 \%)$.

The included studies reported high, similar readmission rates for HF between $42 \%$ and $44,9 \%[26,28,38]$.

Of the included articles, two separated the cost data by gender $[28,29]$ and both reported higher costs for women.

\section{Cost components}

To enable better comparability, prevalence-based studies were grouped separately from the incidence-based ones.

\section{Cost components of the prevalence-based approach}

The cost components of the included studies were subject to large variations (Table 3). Most of the articles considered the economic burden of HF only in terms of direct costs, such as costs attributed to hospitalization, medication, home care, etc. Two studies [31, 37] additionally accounted for the costs of informal care. Informal caregiving was defined as care provided by individuals who were not professional social or health care workers [37]. The indirect costs in terms of loss of productivity 
Table 2 Main data sources and definition of HF in the included studies

\begin{tabular}{|c|c|c|}
\hline Study & Main data sources & Definition of HF \\
\hline Voigt, 2014 [35] & $\begin{array}{l}\text { Agency for Healthcare Research and Quality (AHRQ) } \\
\text { National Association for Home Care \& Hospice (NAHC) } \\
\text { National Ambulatory Medical Care Survey (NAMCS) } \\
\text { National Hospital Ambulatory Medical Care Survey (NHAMCS) } \\
\text { Centers for Medicare \& Medicaid Services (CMS) }\end{array}$ & $\begin{array}{l}\text { ICD-9 (428.x, 402.01, 402.11, 402.91, 398.91, 404.01, } \\
404.11,404.91,416.9,425.4,518.4,786)\end{array}$ \\
\hline Corrao, 2014 [33] & Italian National Health System (NHS) database from Lombardy & ICD-9 $(428,402.01,402.11,402.91)$ \\
\hline Czech, 2013 [36] & $\begin{array}{l}\text { Medical data from randomly selected outpatient units and inpatient } \\
\text { facilities linked with patient interview data (POLKARD study) }\end{array}$ & - \\
\hline Delgado, 2013 & $\begin{array}{l}\text { Medical records from specialized cardiology clinics, questionnaires } \\
\text { and interviews (patients and caregivers) }\end{array}$ & $\begin{array}{l}\text { Symptomatic patients (NYHA II-IV) with a diagnosis } \\
\text { of HF at least } 6 \text { months previously }\end{array}$ \\
\hline Dunlay, 2011 [34] & $\begin{array}{l}\text { Medical records and billing data from Olmsted County Healthcare } \\
\text { Expenditure and Utilization Database (OCHEUD), a population-based } \\
\text { database in Olmsted County, Minnesota, USA }\end{array}$ & ICD-9 (428) \\
\hline Bogner, 2010 [24] & $\begin{array}{l}\text { Administrative database of a large urban academic health care } \\
\text { system } \\
\text { Medicare claims database }\end{array}$ & ICD-9 (428.0, 428.1, 428.9, 402.01, 402.11, 402.91) \\
\hline Zugck, 2010 [30] & $\begin{array}{l}\text { Database of the public health insurance, cohort selected by } \\
\text { randomly prescribed date of birth } \\
\text { Federal Office of Statistics, Germany }\end{array}$ & ICD-10 (I50) \\
\hline Neumann, 2009 [29] & Federal Office of Statistics, Germany & ICD-10 (I50) \\
\hline $\begin{array}{l}\text { Liao, } 2007[23] \\
\text { Liao, } 2006[25]\end{array}$ & $\begin{array}{l}\text { Cardiovascular Health Study (prospective, community-based, } \\
\text { observational study) } \\
\text { Medicare linked files }\end{array}$ & $\begin{array}{l}\text { Hospitalization for HF or self-report of a physician } \\
\text { diagnosis of HF }\end{array}$ \\
\hline Agvall, 2005 [28] & $\begin{array}{l}\text { Hospital records from two healthcare centers } \\
\text { Swedish National Medical Agency price list }\end{array}$ & ICD-10 (150) \\
\hline Ory, 2005 [26] & $\begin{array}{l}\text { Longitudinal database of Prescription Solutions, } \\
\text { a pharmacy benefit and medical management organization }\end{array}$ & $\begin{array}{l}\text { ICD-9 (398.91, 402.01, 402.11, 402.91, 404.01, 404.03, } \\
404.11,404.91)\end{array}$ \\
\hline Stafylas, 2016 & $\begin{array}{l}\text { EURObservational Research Programme: The Heart Failure Pilot } \\
\text { Survey (ESC-HF Pilot) } \\
\text { EOPYY- Greek National Organization for Health Care Provision }\end{array}$ & $\begin{array}{l}\text { Hospitalization for HF or HF diagnosis according to } \\
\text { clinical judgement of the responsible cardiologist }\end{array}$ \\
\hline Lee, 2016 [31] & $\begin{array}{l}\text { Claims data from the National Health Insurance (NHI) } \\
\text { Claims data from Medical Aid (MA) }\end{array}$ & ICD-10 (I11.0, I13.0, I13.2, I50.x) \\
\hline Murphy, 2016 & National Casemix Program, patient interviews, hospital records & ICD-10 \\
\hline Ogah, 2014 [32] & Abeokuta HF registry (hospital registry), patient interviews & ICD-10 \\
\hline
\end{tabular}

were considered only by three studies [31, 32, 35]. Lee et al. [31] calculated caregiver's costs as the product of the average annual inpatient days per patient due to HF and the average market price for the daily charge of a helper. He also calculated indirect costs in terms of productivity loss due to morbidity and mortality for ages under 65 by using mathematical equations derived from the human capital approach.

In the prospective, observational study Delgado et al. [37] estimated the costs of informal care by recording the hours of caregiving provided. The maximum number of caregiving hours per person was limited to 112 (16 h per day for 7 days of caregiving weekly). The number of hours was multiplied with the mean costs of an hour of home care.

Ogah et al. [32] calculated the costs for productivity loss by recording the days of lost work and multiplying them with the minimum wage.

Among the aspects of direct costs, hospital admission and medication were examined in most of the papers.
Agvall et al. [28] and Czech et al. [36] estimated the costs for treatment in intensive care units apart from the hospitalization costs. There were also differences in the outpatient care cost components. Whereas most of the included studies reported costs for outpatient medication and physician visits, five articles reported cost data for laboratory and procedures [28, 29, 32-34, 38] such as speech and physical therapy. The economic burden of home care was estimated by Voigt and Delgado et al. $[35,37]$. Home care referred to care which was provided by professional caregivers at home.

\section{Cost components of the incidence-based group}

In comparison to the prevalence-based group, the articles with an incidence-based or mixed approach have less cost components (Table 3). All studies included costs for inpatient care, and all except one [25] considered the costs for medication. None of the studies estimated the costs 
Table 3 Summary of the cost components (studies with an incident and mixed approach are underlined)

\begin{tabular}{|c|c|c|c|c|c|c|c|c|c|c|c|c|c|c|c|c|}
\hline Cost components & (37) & (29) & (36) & (35) & (28) & (23) & (24) & (30) & (38) & (31) & (32) & (27) & (34) & (33) & (26) & (25) \\
\hline Direct costs & $\checkmark$ & $\checkmark$ & $\checkmark$ & $\checkmark$ & $\checkmark$ & $\checkmark$ & $\checkmark$ & $\checkmark$ & $\checkmark$ & $\checkmark$ & $\checkmark$ & $\checkmark$ & $\checkmark$ & $\checkmark$ & $\checkmark$ & $\checkmark$ \\
\hline Inpatient care & $\checkmark$ & $\checkmark$ & $\checkmark$ & $\checkmark$ & $\checkmark$ & $\checkmark$ & $\checkmark$ & $\checkmark$ & $\checkmark$ & $\checkmark$ & $\checkmark$ & $\checkmark$ & $\checkmark$ & $\checkmark$ & & $\checkmark$ \\
\hline Medication & & & & $\checkmark$ & & & $\checkmark$ & $\checkmark$ & $\checkmark$ & $\checkmark$ & $\checkmark$ & $\checkmark$ & $\checkmark$ & & & \\
\hline Laboratory & & & & & & & & & $\checkmark$ & & $\checkmark$ & & $\checkmark$ & & & \\
\hline Physicians & & & & $\checkmark$ & & & & & $\checkmark$ & & & & & & & \\
\hline Intensive care units & & & $\checkmark$ & & $\checkmark$ & & & & & & & & & & & \\
\hline Nursing home & $\checkmark$ & $\checkmark$ & & $\checkmark$ & $\checkmark$ & & & & & & & & & & & \\
\hline Outpatient care & $\checkmark$ & $\checkmark$ & $\checkmark$ & $\checkmark$ & $\checkmark$ & $\checkmark$ & $\checkmark$ & $\checkmark$ & $\checkmark$ & $\checkmark$ & $\checkmark$ & $\checkmark$ & $\checkmark$ & $\checkmark$ & & $\checkmark$ \\
\hline Hospital Outpatient care & & & & $\checkmark$ & $\checkmark$ & & & & & & $\checkmark$ & & & & & \\
\hline Physicians & $\checkmark$ & $\checkmark$ & $\checkmark$ & $\checkmark$ & $\checkmark$ & & & & $\checkmark$ & & & $\checkmark$ & $\checkmark$ & & & \\
\hline Specialist & $\checkmark$ & & & & & & & & & & & & & & & \\
\hline Home care & $\checkmark$ & & & $\checkmark$ & & & & & & & & & & & & \\
\hline Medication & $\checkmark$ & $\checkmark$ & $\checkmark$ & $\checkmark$ & $\checkmark$ & & & $\checkmark$ & $\checkmark$ & $\checkmark$ & $\checkmark$ & & & $\checkmark$ & $\checkmark$ & \\
\hline Laboratory /Procedures & & & & & $\checkmark$ & & & & $\checkmark$ & & $\checkmark$ & & $\checkmark$ & $\checkmark$ & & \\
\hline Paramedical staff & & $\checkmark$ & & $\checkmark$ & $\checkmark$ & & & & & & & & & & & \\
\hline Medical transport & $\checkmark$ & $\checkmark$ & & & & & & & & $\checkmark$ & $\checkmark$ & & & & & \\
\hline Indirect costs & & & & $\checkmark$ & & & & & & $\checkmark$ & $\checkmark$ & & & & & \\
\hline Informal care costs & $\checkmark$ & & & & & & & & & $\checkmark$ & & & & & & \\
\hline
\end{tabular}

for home care, nursing homes, informal caregiving or indirect costs.

\section{Cost estimates}

The main economic estimates are presented in Table 4. The total annual costs per patient ranged from $\$ 868$ for South Korea [31] to $\$ 25,532$ for Germany [30]. Two articles $[29,35]$ accounted the costs not per patient, but analyzed the whole economic burden of HF per year in an aggregated way. The hospitalization costs are the greatest cost component of overall healthcare costs. Among total healthcare costs, expenditures for medication are the second largest issue [33, 37]. Due to hospitalization costs, room and board were the greatest contributor (43\% of inpatient costs), following by procedures, imaging and laboratory testing [34]. Dialysis was responsible for the highest part of procedural costs, but it was needed only by a small number of patients [34].

The study of Delgado et al. [37] considered the burden of costs of informal caregiving per patient. He estimated that 59.1 to $69,8 \%$ were due to informal care costs. Additionally, he showed that the healthcare and informal care costs for HF were rapidly increasing with the number of hospital admissions, contributing to overall increases in total costs for HF. Of the included studies Dunlay et al. [34] presented the lifetime costs for HF for the longest study period.

Ory et al. [26] reported that newly diagnosed patients had significantly higher healthcare charges than the prevalent group. Furthermore, he described that - in comparison to the control group without HF- the patients with HF created four times higher total healthcare costs.

The study of Ogah et al. [32] was the only one conducted in a low/middle income country (Nigeria). 46\% of the total costs were contributable to inpatient and $54 \%$ to outpatient costs [32]. Inpatient costs were lower than in high-income countries because in these countries the utilization of expensive medical equipment and surgery are higher. Ogah et al. [32] showed that $90 \%$ of direct outpatient costs are due to medication and transportation costs for monthly follow-up visits, which were mostly made through out-of-pocket payments.

\section{Predictors of increasing costs}

Some studies estimated cost predictors, which are shown in Table 5. A higher NYHA stage [23, 25, 37, 38], kidney dysfunction $[25,38]$ and the comorbidity of HF and diabetes mellitus [24, 34] were considered as the most common reasons of increasing costs for HF patients. Two studies [23, 33] reported that that comorbid conditions of HF were much more associated with greater costs than prevalent HF alone. Comorbidities in HF cause $3 / 4$ of all readmissions in HF patients [33]. Dunlay et al. [34] conducted a study with an incident epidemiological approach and analyzed that diabetes mellitus caused an increase in lifetime costs of HF patients of $25 \%$. Bogner et al. [24] also emphasized that diabetes mellitus has substantial influence on the costs of managing HF patients, extends the hospital stay and worsens the prognosis. A study analyzed that a preserved ejection fraction $(>=50 \%)$ in $\mathrm{HF}$ patients leads 
Table 4 Summary of cost estimates (studies with an incident and mixed approach are underlined)

\begin{tabular}{|c|c|c|c|c|c|c|c|}
\hline Reference & $\begin{array}{l}\text { Year of } \\
\text { cost data }\end{array}$ & Country & $\begin{array}{l}\text { Reported annual } \\
\text { costs in local currency } \\
\text { (costs per patient) }\end{array}$ & $\begin{array}{l}\text { Local currency in } \\
2016\end{array}$ & \$US (2016 PPP) & $\begin{array}{l}\% \text { of inpatient } \\
\text { costs of all } \\
\text { direct costs }\end{array}$ & $\begin{array}{l}\text { Expenditure on } \\
\text { health, per capita, } \\
\text { US\$ (2016 PPP) }\end{array}$ \\
\hline Voigt, 2014 [35] & 2012 & USA & $\begin{array}{l}\$ 60.2-\$ 115.4 b^{a} \\
\text { (direct costs) } \\
\$ 70.8-\$ 127.0 b^{a} \\
\text { (total costs) }\end{array}$ & $\begin{array}{l}\$ 62.9-\$ 120.7 b^{a} \\
\$ 74.0-\$ 133.0 b^{a}\end{array}$ & $\begin{array}{l}62.9-120.7 b^{a} \\
74.0-133.0 b^{a}\end{array}$ & 66 & 9892 \\
\hline Czech, 2013 [36] & 2010 & Poland & 7739 PLN & 8312 PLN & 4755 & $92^{\mathrm{e}}$ & 1798 \\
\hline Delgado, 2013 & 2010 & Spain & $\begin{array}{l}4860 € \\
\text { (healthcare costs) }\end{array}$ & $5166 €$ & 7792 & $58^{e}$ & 3248 \\
\hline Bogner, 2010 [24] & 2009 & USA & $22,230 \$^{b}$ & $24,873 \$^{b}$ & $24,873^{b}$ & 84 & 9892 \\
\hline Zugck, 2010 [30] & 2002 & Germany & $11,794-16,303 €^{c}$ & $14,297-19,762 €^{c}$ & $18,472-25,532^{c}$ & 72 & 5551 \\
\hline Neumann, 2009 [29] & 2006 & Germany & $2.879 b €^{a}$ & $3.293 b €^{a}$ & $4.255 b^{a}$ & 60 & 5551 \\
\hline Liao, 2007 [23] & 2006 & USA & $\$ 10,832$ & $12,907 \$$ & 12,907 & $65^{\mathrm{e}}$ & 9892 \\
\hline Agvall, 2005 [28] & 2000 & Sweden & 37,060 SEK & 44,971 SEK & 5044 & 47 & 5488 \\
\hline Stafylas, 2016 & 2014 & Greece & $4411 €$ & $4295 €$ & 7053 & $73^{\mathrm{e}}$ & 2223 \\
\hline Ogah, 2014 [32] & 2010 & Nigeria & $2128 \$$ & $2343 \$$ & 2343 & 44 & NA \\
\hline Lee, 2016 [31] & 2016 & South Korea & $\begin{array}{l}868 \$ \text { (perspective of } \\
\text { third-party-payer) } \\
1414 \$ \text { (perspective } \\
\text { of society) }\end{array}$ & $\begin{array}{l}868 \$ \\
1414 \$\end{array}$ & $\begin{array}{l}868 \\
1414\end{array}$ & 53 & NA \\
\hline Dunlay, 2011 [34] & 2007 & USA & $\begin{array}{l}109.541 \$ \text { (lifetime costs from } \\
\text { HF diagnosis until death) }\end{array}$ & $126.819 \$$ & 126.819 & 77 & 9892 \\
\hline Corrao, 2014 [33] & 2011 & Italy & $11,100 €$ & $11,597 €$ & 15,952 & $92^{\mathrm{e}}$ & 3391 \\
\hline Liao, 2006 [25] & 2000 & USA & $\begin{array}{l}32,580-33,023 \$ \\
\text { (prevalent group) }^{d} \\
45,604-49,128 \$ \\
\text { (incident group) }^{d}\end{array}$ & $\begin{array}{l}45,406-46,023 \$^{d} \\
63,557-68,468 \$^{d}\end{array}$ & $\begin{array}{l}45,406-46,023^{d} \\
63,557-68,468^{d}\end{array}$ & $\begin{array}{l}65-67 \\
70-72\end{array}$ & 9892 \\
\hline Ory, 2005 [26] & 2000 & USA & $\begin{array}{l}14,465 \$ \text { (prevalent group) } \\
17,744 \$ \text { (incident group) }\end{array}$ & $\begin{array}{l}20,159 \$ \\
24,729 \$\end{array}$ & $\begin{array}{l}20,159 \\
24,729\end{array}$ & NA & 9892 \\
\hline Murphy, 2016 & 2013 & Ireland & $\begin{array}{l}12,206 € \text { (patients with } \\
\text { preserved EF) } \\
13,011 € \text { (patients with } \\
\text { reduced EF) }\end{array}$ & $\begin{array}{l}12,194 € \\
12,999 €\end{array}$ & $\begin{array}{l}15,334 \\
16,330\end{array}$ & $\begin{array}{l}92^{e} \\
96^{e}\end{array}$ & 5528 \\
\hline
\end{tabular}

\footnotetext{
${ }^{\mathrm{a}}$ Aggregated costs for all HF patients

${ }^{b}$ Costs aggregated for two years

${ }^{c}$ Costs depend on number of visits to doctors

${ }^{\mathrm{d} C}$ Cumulated costs for 5 years

enot clearly stated in the study

SEK Swedish kronas, PLN Polish Zloty, $b$ Billions, EF ejection fraction
}

to an increasing cost impact of $24 \%$ [34]. In contrast, Liao et al. [25] showed that there was no statistically significant difference between HF patients with normal and reduced EF due to the 5 -year cumulative costs.

The severity of HF is classified by NYHA (New York Heart Association) stages [1]. Of the included studies, only two $[36,37]$ separated the cost data by NYHA stage (Table 6). Czech et al. [36] gave very detailed information on cost data by NYHA class I-IV, estimating the total annual costs as well as the average costs of hospitalization for HF by NYHA stage. Delgado et al. [37] reported economic data for NYHA stages II-IV and estimated the total costs for HF by combining the NYHA groups III and IV. $\mathrm{He}$ emphasized the rising costs and the significantly increased use of health services and social services, as formal and informal care, by NYHA stage. Both studies showed that the economic burden of HF is dependent on the NYHA stage and the costs rise with advanced stages, disregarding NYHA stage I. Thus, it is important to act early and to prevent the progression of HF to more advanced and highly symptomatic forms. Czech et al. [36] reported for NYHA I high annual as well as hospitalization costs and assumed that this could be attributable to the higher proportion of special cardiology interventions in this group. Additionally, he described that NYHA IV was responsible for more than $70 \%$ of total annual costs for HF.

\section{Distribution of costs}

Two articles [25, 34] compared the cost data of patients in the first year of HF diagnosis to the previous year in 
Table 5 Predictors of increasing costs

\begin{tabular}{|c|c|}
\hline Reference & Predictors of increasing costs ( $x$ times higher costs) \\
\hline Stafylas, 2016 & $\begin{array}{l}\text { - NYHA stage } \\
\text { - Kidney dysfunction }\end{array}$ \\
\hline Lee, 2016 [31] & $\begin{array}{l}\text { - Age }>=65 \text { (1.6) } \\
\text { - Number of hospitalizations } \\
\text { (9.7 for one hospitalization) }\end{array}$ \\
\hline Bogner, 2010 [24] & - Diabetes mellitus (0.4) \\
\hline Dunlay, 2011 [34] & $\begin{array}{l}\text { - Diabetes mellitus }(0.25) \\
\text { - Ejection fraction }>=50(0.24)\end{array}$ \\
\hline Liao, 2006 [25] & $\begin{array}{l}\text { - NYHA stage (NYHA 4-0.77, NYHA 3-0.12) } \\
\text { - Kidney dysfunction } \\
\text { (creatinine }>=1.4 \mathrm{mg} / \mathrm{dl}-0.48) \\
\text { - Coronary artery disease }(0.32) \\
\text { - COPD }(0.38) \\
\text { - Hypertension }(0.27)\end{array}$ \\
\hline Liao, 2007 [23] & $\begin{array}{l}\text { - NYHA stage (NYHA } 3 / 4-0.41) \\
\text { - Coronary artery disease }(0.66) \\
\text { - Kidney dysfunction }(0.13) \\
\text { - COPD }(0.44)\end{array}$ \\
\hline Delgado, 2013 & $\begin{array}{l}\text { - NYHA stage (NYHA 3/4: 0.6-0.8 times } \\
\text { higher costs than NYHA 2) }\end{array}$ \\
\hline
\end{tabular}

order to investigate the impact of $\mathrm{HF}$ on the costs (Table 7). Dunlay et al. [34] reported an 318\% increase in costs in the year of HF diagnosis. He also examined that the costs for HF were high at the time of initial diagnosis, decreased then, reached a stable, relative low level and increased again at the end of life. Liao et al. [25] estimated in his study that the development of HF had a greater than $200 \%$ increase in total costs compared to the year before diagnosis. This strong rise was especially generated by the inpatient cost component. After that he detected a decrease of costs, but they were still higher than in the year before HF diagnosis out to year 5 , if only survivors were examined.

\section{Discussion}

Our systematic review highlights the economic impact of $\mathrm{HF}$ as a rising burden for high-income countries.
Furthermore, it also uncovers the large heterogeneity of COI studies focused on HF.

\section{Comparison of the cost data}

The main findings of our review are reported in Table 4 and are focused on the highest annual per-patient costs reported for the USA [24] and Germany [30]. Our review shows that the costs for hospital admission contribute significantly to the overall direct costs for HF (ranging from 44 to $96 \%$ ). Previously published studies accounted that about two-thirds of the direct HF healthcare costs are due to hospitalization $[6,39]$. The high inpatient costs are a result of high readmission rates, with $23 \%$ of HF patients readmitted to hospital stay within 6 months [6]. A further aspect of our analyses is the considerable increase in costs with advanced NYHA stage, with NYHA stage IV being the most expensive. Biermann et al. [5] estimated similar results for patients with systolic HF. An earlier review [40] estimated that patients with NYHA IV produce between 8 and 30 times higher healthcare costs than patients with NYHA II. We have shown that costs rise rapidly after a confirmed HF diagnosis (Table 7). Although HF is a chronic condition causing high lifetime costs, particularly the first year after a HF diagnosis and the end-of-life care are the most expensive ones. Two studies from the USA [41] and Canada [42] analyzed the last 180 days of life of HF patients and concluded that in the last six months of life, there is a large increase in costs and resource use. Unroe et al. [41] as well as Kaul et al. [42] analyzed that the costs during the last 180 days rose from $\$ 28,766$ to $\$ 36,215$ between the years 2000-2007 for the USA [41] and from $\$ 25,069$ to $\$ 27,983$ (Canadian dollars) between the years 2000-2006 for Canada [42].

Other studies also report a rise in costs relating to HF over time, but especially in the last two decades. Stewart et al. [39] reported a rise of direct medical costs from

Table 6 Costs by NYHA stage

\begin{tabular}{|c|c|c|c|c|c|c|c|}
\hline \multirow[t]{2}{*}{ Reference } & \multirow[t]{2}{*}{ Year of cost data } & \multirow[t]{2}{*}{ Country } & NYHA I & NYHA II & NYHA III & NYHA IV & $\begin{array}{l}\text { Total costs per } \\
\text { patient and year }\end{array}$ \\
\hline & & & \multicolumn{5}{|c|}{$\begin{array}{l}\text { local currency in year of costs/ } \\
\text { local currency in 2016/ } \\
\text { \$US in 2016, PPP }\end{array}$} \\
\hline $\begin{array}{l}\text { Delgado, } 2013 \\
\text { (direct costs) }\end{array}$ & 2010 & Spain & - & $\begin{array}{l}3789 € / \\
4028 € / \\
6075 \$\end{array}$ & $\begin{array}{l}6832 € / \\
7262 € / \\
10,953 \$\end{array}$ & & $\begin{array}{l}4860 € / \\
5166 € / \\
7792 \$\end{array}$ \\
\hline $\begin{array}{l}\text { Delgado, } 2013 \\
\text { (total costs) }\end{array}$ & 2010 & Spain & - & $\begin{array}{l}10,283-14,459 € / \\
10,931-15,370 € / \\
16,487-23,183 \$\end{array}$ & $\begin{array}{l}18,265-23,721 € / \\
19,416-25,215 € / \\
29,285-38,032 \$\end{array}$ & & $\begin{array}{l}12,995-18,220 € / \\
13,814-19,368 € / \\
20,836-29,213 \$\end{array}$ \\
\hline Czech, 2013 [36] & 2010 & Poland & a & $\begin{array}{l}5,315 \mathrm{PLN} / \\
5,708 \mathrm{PLN} / \\
3265 \$\end{array}$ & $\begin{array}{l}\text { 8,116PLN/ } \\
8,717 \mathrm{PLN} / \\
4987 \$\end{array}$ & $\begin{array}{l}21,273 \mathrm{PLN} / \\
22,847 \mathrm{PLN} / \\
13,070 \$\end{array}$ & $\begin{array}{l}\text { 7739PLN/ } \\
\text { 8312PLN/ } \\
4755 \$\end{array}$ \\
\hline
\end{tabular}

a Costs are reported, but not listed here

PLN Polish Zloty 
Table 7 Comparison of costs

\begin{tabular}{|c|c|c|c|c|c|c|c|c|}
\hline Reference & $\begin{array}{l}\text { Year of } \\
\text { costs }\end{array}$ & Country & $\begin{array}{l}\text { Year prior to } \\
\text { HF diagnosis }\end{array}$ & $\begin{array}{l}\text { Year beginning } \\
\text { with HF diagnosis }\end{array}$ & $\begin{array}{l}\text { Difference in costs } \\
\text { (local currency in } \\
\text { year of costs) }\end{array}$ & $\begin{array}{l}\text { Difference in costs } \\
\text { (local currency in 2016) }\end{array}$ & $\begin{array}{l}\text { Difference in costs } \\
(\$ \cup S \text { in 2016, PPP) }\end{array}$ & $\begin{array}{l}\text { Raise of the } \\
\text { costs in } \%\end{array}$ \\
\hline Dunlay, 2011 [34] & 2007 & USA & $8219 \$$ & $34,372 \$$ & $26,153 \$$ & $30,278 \$$ & 30,278 & 318 \\
\hline Liao, 2006 [23] & 2000 & USA & $6650-6752 \$$ & $24,882-25,503 \$$ & $18,232-18,751 \$$ & $25,409-26,133 \$$ & $25,409-26,133$ & $274-278$ \\
\hline
\end{tabular}

$£ 716$ million in 1995 to $£ 905$ million in 2000 for the UK. Liao et al. [6] presented an increase of HF-related costs for different countries (Spain, Canada, Sweden and Scotland) by $40-71 \%$.

\section{The need for standards for future COI-studies in HF}

Our review highlighted not only the large economic burden of HF, but also the heterogeneity of the studies and lack of cost data. For better comparison of research data, future COI studies should use a standardized approach regarding methodology, in particular regarding criteria concerning the selection of HF patients and data, the inclusion of different cost drivers and the presentation of results.

Thus, further COI studies in HF should clearly state the ICD codes, which were used for identification of HF patients. Additionally, an attribution of cost data to the specific ICD code number could achieve a better comparison between COI studies. As presented in recently published papers, using different ICD codes may lead to an over- or underestimation of HF diagnosis [43, 44].

COI studies should present cost data for the whole HF group and disaggregate them consistently for sub-entities, as systolic or diastolic HF. Importantly, COI studies should emphasize clearly stating the use of the exact diagnoses (including relevant ICD codes). It should be clearly stated, if HF is defined as the primary or secondary diagnosis, as this difference influences the cost estimates. The inclusion of comorbidities would give detailed information on the cost drivers and show opportunities for decreasing costs.

In addition, the study perspective and a distinction between COI approaches should be indicated [18]. This review emphasizes that indirect costs are a significant contributor to total costs and more effort is needed to estimate these costs accurately and consistently. In addition, informal care costs are an important contributor to the COI of HF [37].

As there are many differences between healthcare systems in different countries, high-quality cost data is needed from COI studies to facilitate comparisons between countries and cost trends. Crucially, more robust data from future COI studies is needed to provide a sound basis for cost-effectiveness studies to identify the most costeffective therapies.

Another aspect in our systematic review highlights that most of the studies are conducted in Europe and USA.
But as HF is a global problem, we need more COI-studies from low-and middle-income countries as demanded in a recently published study [45].

\section{Study limitations}

The cost data we included in our systematic review derived from a heterogeneous set of studies with different methodologies used, to collect the data. This lack of a standard method for collecting the cost data may impact some of our findings. The included studies were conducted in different countries with various healthcare systems. This may lead to an over- or underestimation of some cost data, as the included studies not clearly describe, which costs are included in their analyses. For example, some studies present the costs in a detailed way, whereas other studies aggregate particular costs to one cost position.

\section{Conclusion}

Our review highlights the considerable and growing economic burden of HF on the health care systems of industrialized countries. The trend for rising costs has especially been more significant during the last 20 years and future demographic developments predict more dramatic rises in the future. Due to the high economic burden of HF -especially in terms of inpatient costs- we need more compelling and innovative strategies to counteract the effects of HF. Reducing admission rates in acute HF is the most promising approach to decrease the economic burden of HF. In this context telemonitoring devices like a wireless pulmonary artery pressure monitoring system are promising new innovations [46-48]. As reported in a recently published study [49] this device has the potential to reduce the hospitalization rates for symptomatic $\mathrm{HF}$ by $37 \%$ and to lead to a significant cost reduction. The COI studies included in this review showed large variations in methodology used and the cost results vary as a consequence. Future COI studies would greatly benefit from a detailed presentation of cost components. Our review shows that there is a lack on cost data and further research is needed to highlight the economic burden of indirect costs of HF. High quality data from COI studies with a robust methodology applied can inform policy makers about the major cost drivers of $\mathrm{HF}$ and can be used as the basis of further economic evaluations. 


\section{Additional files}

Additional file 1: List of search terms, databases and results of each search. (DOCX $13 \mathrm{~kb}$ )

Additional file 2: Criteria used for inclusion/exclusion of reviewed articles. (DOCX $14 \mathrm{~kb}$ )

\section{Abbreviations}

COI: Cost-of-Illness; HF: Heart failure; NYHA: New York Heart Association

\section{Acknowledgements}

The present work was performed in fulfillment of the requirements for obtaining the degree "Dr. med." for author Wladimir Lesyuk at the Medical Faculty of Friedrich-Alexander-University Erlangen-Nürnberg.

\section{Funding}

This project was funded by the German Federal Ministry of Education Research (BMBF) as part of the National Cluster of Excellence "Medica Technologies - Medical Vallex EMN" (Project grant No. 13EX1013B).

\section{Availability of data and materials}

All data generated or analysed during this study are included in this published article and its supplementary information files.

\section{Authors' contributions}

WL collected, analysed and interpreted the data. He was also a major contributor in writing the manuscript. CK checked the data results. PK supervised and corrected the work. All authors read and approved the final manuscript.

\section{Ethics approval and consent to participate}

Not applicable.

\section{Competing interests}

The authors declare that they have no competing interests.

\section{Publisher's Note}

Springer Nature remains neutral with regard to jurisdictional claims in published maps and institutional affiliations.

Received: 5 November 2017 Accepted: 20 April 2018

Published online: 02 May 2018

\section{References}

1. Dickstein K, Cohen-Solal A, Filippatos G, McMurray JJ, Ponikowski P, PooleWilson PA, et al. ESC guidelines for the diagnosis and treatment of acute and chronic heart failure 2008: the task force for the diagnosis and treatment of acute and chronic heart failure 2008 of the European Society of Cardiology. Developed in collaboration with the heart failure association of the ESC (HFA) and endorsed by the European Society of Intensive Care Medicine (ESICM). Eur Heart J. 2008;29(19):2388-442.

2. Redfield MM, Jacobsen SJ, Burnett JC Jr, Mahoney DW, Bailey KR, Rodeheffer RJ. Burden of systolic and diastolic ventricular dysfunction in the community: appreciating the scope of the heart failure epidemic. JAMA. 2003;289(2):194-202.

3. Remme WJ, Swedberg K. Guidelines for the diagnosis and treatment of chronic heart failure. Eur Heart J. 2001:22(17):1527-60.

4. Go AS, Mozaffarian D, Roger VL, Benjamin EJ, Berry JD, Blaha MJ, et al. Heart disease and stroke statistics-2014 update: a report from the American Heart Association. Circulation. 2014;129(3):e28-e292.

5. Biermann J, Neumann T, Angermann CE, Düngen HD, Erbel R, Herzog W, et al. Resource use and costs in systolic heart failure according to disease severity: a pooled analysis from the German competence network heart failure. Journal of Public Health (Germany). 2012;20(1):23-30.

6. Liao L, Allen LA, Whellan DJ. Economic burden of heart failure in the elderly. PharmacoEconomics. 2008;26(6):447-62.

7. Braunschweig F, Cowie MR, Auricchio A. What are the costs of heart failure? Europace : European pacing, arrhythmias, and cardiac electrophysiology : Journal of the working groups on cardiac pacing, arrhythmias, and cardiac cellular electrophysiology of the European Society of Cardiology. 2011;13 Suppl 2:ii13-ii17.

8. Bundkirchen A, Schwinger RHG. Epidemiology and economic burden of chronic heart failure. European Heart Journal, Supplement. 2004;6(D):D57-60.

9. Reed SD, Whellan DJ, Li Y, Friedman JY, Ellis SJ, Pina IL, et al. Economic evaluation of the HF-ACTION (heart failure: a controlled trial investigating outcomes of exercise training) randomized controlled trial: an exercise training study of patients with chronic heart failure. Circulation Cardiovascular quality and outcomes. 2010;3(4):374-81.

10. Pocock SJ, Ariti CA, McMurray JJ, Maggioni A, Kober L, Squire IB, et al. Predicting survival in heart failure: a risk score based on 39372 patients from 30 studies. Eur Heart J. 2013;34(19):1404-13.

11. Ranasinghe I, Wang Y, Dharmarajan K, Hsieh AF, Bernheim SM, Krumholz HM. Readmissions after hospitalization for heart failure, acute myocardial infarction, or pneumonia among young and middle-aged adults: a retrospective observational cohort study. PLoS Med. 2014;11(9):e1001737.

12. Cook C, Cole G, Asaria P, Jabbour R, Francis DP. The annual global economic burden of heart failure. Int J Cardiol. 2014;171(3):368-76.

13. Wimo A. The art of cost of illness. Journal of Alzheimer's disease : JAD. 2010;19(2):617-9.

14. Wang XJ, Lopez SE, Chan A. Economic burden of chemotherapy-induced febrile neutropenia in patients with lymphoma: a systematic review. Crit Rev Oncol Hematol. 2015;94(2):201-12.

15. Larg A, Moss JR. Cost-of-illness studies: a guide to critical evaluation. PharmacoEconomics. 2011;29(8):653-71.

16. Moher D, Altman DG, Liberati A, Tetzlaff J. PRISMA statement. Epidemiology (Cambridge, Mass). 2011;22(1):128. author reply

17. Evers $\mathrm{S}$, Goossens $\mathrm{M}$, de Vet $\mathrm{H}$, van Tulder M, Ament A. Criteria list for assessment of methodological quality of economic evaluations: consensus on health economic criteria. Int J Technol Assess Health Care. 2005:21(2):240-5.

18. Drummond MF, Jefferson TO. Guidelines for authors and peer reviewers of economic submissions to the BMJ. The BMJ economic evaluation working party. BMJ (Clin Res ed). 1996;313(7052):275-83.

19. Owan TE, Hodge DO, Herges RM, Jacobsen SJ, Roger VL, Redfield MM. Trends in prevalence and outcome of heart failure with preserved ejection fraction. N Engl J Med. 2006:355(3):251-9.

20. OECD. Consumer Price Index. 2016

21. OECD. PPP. 2016.

22. Payne KA, Huybrechts KF, Caro JJ, Craig Green TJ, Klittich WS. Long term cost-of-illness in stroke: an international review. PharmacoEconomics. 2002; 20(12):813-25

23. Liao L, Anstrom KJ, Gottdiener JS, Pappas PA, Whellan DJ, Kitzman DW, et al. Long-term costs and resource use in elderly participants with congestive heart failure in the cardiovascular health study. Am Heart J. 2007;153(2):245-52.

24. Bogner HR, Miller SD, de Vries HF, Chhatre S, Jayadevappa R. Assessment of cost and health resource utilization for elderly patients with heart failure and diabetes mellitus. J Card Fail. 2010;16(6):454-60.

25. Liao L, Jollis JG, Anstrom KJ, Whellan DJ, Kitzman DW, Aurigemma GP, et al. Costs for heart failure with normal vs reduced ejection fraction. Arch Intern Med. 2006;166(1):112-8.

26. Ory C, Vanderplas A, Dezii C, Chang E. Congestive heart failure: attributable costs within the managed care setting. Journal of Pharmaceutical Finance, Economics and Policy. 2005:14(2):87-97.

27. Murphy TM, Waterhouse DF, James S, Casey C, Fitzgerald E, O'Connell E, et al. A comparison of HFrEF vs HFpEF's clinical workload and cost in the first year following hospitalization and enrollment in a disease management program. Int J Cardiol. 2017;232:330-5.

28. Agvall $B$, Borgquist $L$, Foldevi M, Dahlstrom U. Cost of heart failure in Swedish primary healthcare. Scand J Prim Health Care. 2005;23(4):227-32.

29. Neumann T, Biermann J, Neumann A, Wasem J, Ertl G, Dietz R, et al. Heart failure: the commonest reason for hospitalization in Germany - medical and economic perspectives. Dtsch Arztebl Int. 2009:106(16):269-75.

30. Zugck C, Muller A, Helms TM, Wildau HJ, Becks T, Hacker J, et al. Health economic impact of heart failure: an analysis of the nationwide German database. Deutsche medizinische Wochenschrift (1946). 2010;135(13):633-8.

31. Lee $\mathrm{H}_{4} \mathrm{Oh} \mathrm{SH}$, Cho H, Cho HJ, Kang HY. Prevalence and socio-economic burden of heart failure in an aging society of South Korea. BMC CardiovasC Disord. 2016:16(1):215

32. Ogah OS, Stewart S, Onwujekwe OE, Falase AO, Adebayo SO, Olunuga T, et al. Economic burden of heart failure: investigating outpatient and inpatient costs in Abeokuta, Southwest Nigeria. PLoS One. 2014;9(11):e113032. 
33. Corrao G, Ghirardi A, Ibrahim B, Merlino L, Maggioni AP. Burden of new hospitalization for heart failure: a population-based investigation from Italy. Eur J Heart Fail. 2014;

34. Dunlay SM, Shah ND, Shi Q, Morlan B, VanHouten H, Long KH, et al. Lifetime costs of medical care after heart failure diagnosis. Circ Cardiovasc Qual Outcomes. 2011:4(1):68-75.

35. Voigt J, Sasha John M, Taylor A, Krucoff M, Reynolds MR, Michael Gibson C. A reevaluation of the costs of heart failure and its implications for allocation of health resources in the United States. Clin Cardiol. 2014;37(5):312-21.

36. Czech M, Opolski G, Zdrojewski T, Dubiel JS, Wizner B, Bolisega D, et al. The costs of heart failure in Poland from the public payer's perspective. Polish programme assessing diagnostic procedures, treatment and costs in patients with heart failure in randomly selected outpatient clinics and hospitals at different levels of care: POLKARD. Kardiol Pol. 2013;71(3):224-32.

37. Delgado JF, Oliva J, Llano M, Pascual-Figal D, Grillo JJ, Comin-Colet J, et al. Health care and nonhealth care costs in the treatment of patients with symptomatic chronic heart failure in Spain. Rev Esp Cardiol. 2014;67(8):643-50.

38. Stafylas P, Farmakis D, Kourlaba G, Giamouzis G, Tsarouhas K, Maniadakis N, et al. The heart failure pandemic: the clinical and economic burden in Greece. Int J Cardiol. 2017;227:923-9.

39. Stewart S, Jenkins A, Buchan S, McGuire A, Capewell S, McMurray JJ. The current cost of heart failure to the National Health Service in the UK. Eur J Heart Fail. 2002;4(3):361-71.

40. Berry C, Murdoch DR, McMurray JJ. Economics of chronic heart failure. Eur J Heart Fail. 2001;3(3):283-91.

41. Unroe KT, Greiner MA, Hernandez AF, Whellan DJ, Kaul P, Schulman KA, et al. Resource use in the last 6 months of life among medicare beneficiaries with heart failure, 2000-2007. Arch Intern Med. 2011;171(3):196-203.

42. Kaul P, McAlister FA, Ezekowitz JA, Bakal JA, Curtis LH, Quan H, et al. Resource use in the last 6 months of life among patients with heart failure in Canada. Arch Intern Med. 2011;171(3):211-7.

43. Khand AU, Shaw M, Gemmel I, Cleland JG. Do discharge codes underestimate hospitalisation due to heart failure? Validation study of hospital discharge coding for heart failure. Eur J Heart Fail. 2005;7(5):792-7.

44. Goff DC Jr, Pandey DK, Chan FA, Ortiz C, Nichaman MZ. Congestive heart failure in the United States: is there more than meets the I(CD code)? The Corpus Christi heart project. Arch Intern Med. 2000;160(2):197-202.

45. Callender T, Woodward M, Roth G, Farzadfar F, Lemarie JC, Gicquel S, et al. Heart failure care in low- and middle-income countries: a systematic review and meta-analysis. PLoS Med. 2014;11(8):e1001699.

46. Abraham WT, Adamson PB, Bourge RC, Aaron MF, Costanzo MR, Stevenson LW, et al. Wireless pulmonary artery haemodynamic monitoring in chronic heart failure: a randomised controlled trial. Lancet (London, England). 2011; 377(9766):658-66.

47. Abraham WT, Stevenson LW, Bourge RC, Lindenfeld JA, Bauman JG, Adamson PB. Sustained efficacy of pulmonary artery pressure to guide adjustment of chronic heart failure therapy: complete follow-up results from the CHAMPION randomised trial. Lancet (London, England). 2016;387(10017):453-61.

48. Dagres N, Hindricks G. Pulmonary pressure, telemedicine, and heart failure therapy. Lancet (London, England). 2016;387(10017):408-10

49. Kolominsky-Rabas PL, Kriza C, Djanatliev A, Meier F, Uffenorde S, Radeleff J, et al. Health economic impact of a pulmonary artery pressure sensor for heart failure Telemonitoring: a dynamic simulation. Telemed J E Health. 2016;22(10):798-808.

\section{Ready to submit your research? Choose BMC and benefit from:}

- fast, convenient online submission

- thorough peer review by experienced researchers in your field

- rapid publication on acceptance

- support for research data, including large and complex data types

- gold Open Access which fosters wider collaboration and increased citations

- maximum visibility for your research: over $100 \mathrm{M}$ website views per year

At BMC, research is always in progress.

Learn more biomedcentral.com/submissions 